\title{
Conferência: ÉTICA E DESENVOLVIMENTO SUSTENTÁVEL - CAMINHOS PARA A CONSTRUÇÃO DE UMA NOVA SOCIEDADE.
}

\author{
Humberto Maturana Romesín \\ Ximena Paz Dávila Y. \\ Instituto Matriztica \\ Tradução: \\ Karla Demoly \\ Unijuí
}

No início de novembro de 2004, o Sistema FIERGS em parceria com o SESI e com o apoio da ONU, através do Escritório das Nações Unidas contra Drogas e Crime (UNODC); da UFRGS, através do Instituto de Filosofia e Ciências Humanas e do Curso de Especialização em Projetos Sociais e Culturais; e da PUCRS através da Faculdade de Serviço Social, realizou a $1^{a}$ Conferência Internacional de Gestão Social com o objetivo de discutir a eficácia das políticas sociais dos poderes públicos, das empresas e organizações não governamentais. Entre os palestrantes convidados estavam Humberto Maturana e Ximena Paz Dávila. $O$ texto da conferência foi traduzido pela Profa. Karla Demoly.

\section{Maturana:}

Agradecemos pela confiança que têm ao estarem dispostos a escutar o que vamos dizer. A verdade é que para nós esta apresentação é uma aventura já que aborda o tema do social, porém podemos dizer que faremos uma reflexão epistemológica. Tenho a impressão que durante alguns dias vocês discutiram o social na perspectiva de uma ação propriamente dita. Nós não temos um trabalho no espaço da ação social, ainda que na relação com nossa mãe, nós já tenhamos um sistema social. Não aprenderíamos qualquer coisa, não aprenderíamos a não ser a partir da sensibilidade dessa primeira interação social. Talvez minhas preocupações pelo social advêm das experiências sociais que vivi acompanhando-a muitas vezes em seu trabalho.

O que nos propomos fazer é uma reflexão epistemológica. O que vamos apresentar, Ximena e eu, são idéias que possibilitam fazer essa reflexão. Para começar, gostaria de me apresentar. Se pensarmos em Maturana: Maturana, teria seguramente muitas coisas que tenho escrito a mostrar para todos e para todas e não teria o que fazer. Certamente o que tenho escrito tem tido uma recepção muito carinhosa no Brasil evidenciada na corres- pondência a mim endereçada. Quando digo que sou biólogo, o que é certo é que sou uma pessoa interessada pelo viver dos seres vivos desde pequenos e toda esta articulação é minha profissão. A relação com a biologia pode levá-los a pensar no perigo de uma reflexão um tanto restrita. Porém, estou convidando-os a pensar de uma maneira um pouco mais ampla.

Em 1999 nos encontramos Ximena e eu, falava da Biologia do Amor, dizia que o amor é central na convivência. A maior parte dos sofrimentos, senão a totalidade dos que afligem os seres humanos, tem que ver com a negação do amor. E quando perguntavam: - O que fazer? Bem, eu dizia: a primeira consigna é o amor. - E como se faz isso? Eu dizia: ame! E é claro, nada entendiam do que eu queria dizer. O que eu queria dizer não é como Jesus que se levantava e dizia: Amai-vos uns aos outros! Eu não sei o que entendiam na época em que eu formulava esta idéia. O que parecia é que as pessoas não compreendiam o que é isto de amar.

Em algum momento de minhas conversações com Ximena, ela me conta o que faz em seu consultório. Disse-me que tinha observado que toda dor, todo pedido de ajuda é de origem cultural, esta cultura em que vivemos, esta cultura patriar$\mathrm{cal} /$ matriarcal na qual estamos imersos. Falou-me ainda que os dois âmbitos, o âmbito biológico e o âmbito cultural podem dar conta do nosso viver. Diante disso, disse: claro! Fiquei pensando que o que havia me dito era algo crucial. A afirmação de que a dor é de origem cultural é fundamental. É fundamental porque parece que os estudos sobre a dor não priorizam a referência a uma dinâmica relacional. A dor faz referência à possibilidade que este ser tem de viver esta dinâmica relacional. $\mathrm{O}$ que surge a uma pessoa revela a trama relacional à qual pertence, trama que também origina a dor. A partir das conversações que fizemos, sobre este ponto, é que ela se deu conta de que é o mesmo 
que pensar em um movimento, na dinâmica relacional da biologia do conhecer - biologia do amar.

Desde então começamos um trabalho conjunto, a tal ponto que criamos o Instituto Matriztica. A palavra matriz aparece aí com z e significa em castelhano - e, penso que em português também útero: trama de relações que indica nossa intenção de falar das relações que nos dão origem, nos fazem possível e nos conservam no viver. Na perspectiva de um olhar ampliado na biologia e na cultura é que vamos fazer as reflexões que serão apresentadas a seguir.

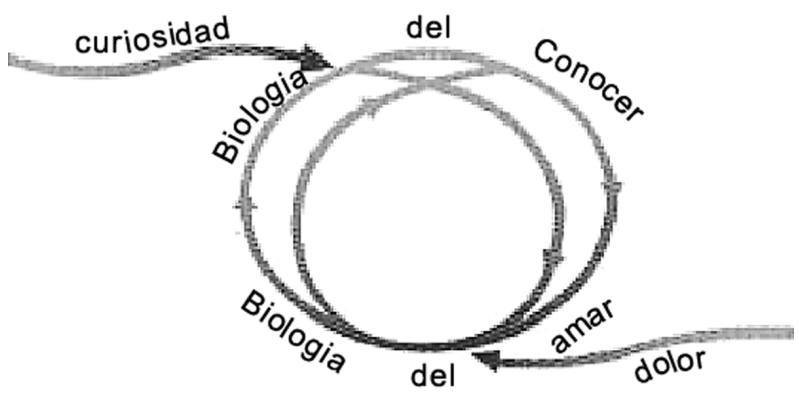

\section{Ximena:}

Vou iniciar minha apresentação. Meu nome é Ximena, sou chilena e meu ofício é conversar. Viemos aqui para conversar sobre como surge a questão social. Quando vínhamos para cá, Maturana e eu conversávamos sobre a diferença entre administrar e gestionar. A gestão implica a administração, ou seja, trabalhar com a trama relacional e a trama emocional, quer dizer, a trama relacional desde onde surge o que fazemos em direção a limites mais amplos. É por essa razão que falaremos dos fundamentos epistemológicos para poder visualizar a questão social em uma visão sistêmica.

\section{Maturana:}

O quadro acima faz referência a uma dinâmica que entrelaça a biologia do amar e a biologia do conhecer. Existe uma possibilidade de entrada (flecha à esquerda) que diz: curiosidade. Quando o ingresso ocorre através de uma pergunta que revela uma curiosidade, pode bifurcar pelo amar. O que se sente põe em jogo a biologia do conhecer e a biologia do amar. O que vamos fazer agora é uma reflexão sobre os fundamentos epistemológicos da transformação social. - O que se põe em jogo? Quais são os fundamentos que estão colocados na dinâmica social em que vivemos? Em uma democracia ou em um autoritarismo? Estas duas palavras estão relacionadas com a história do Brasil e com a história do Chile. Nós vivemos em algum momento da nossa história entre a democracia e o autoritarismo e ambos os países caminham para a democracia, tendo passado pela experiência do autoritarismo. O que está colocado é uma reflexão sobre a experiência dos dois países.

\section{Ximena:}

A epistemologia nos leva a ver os fundamentos que dão origem ao viver. Um fundamento é um modo de ver.

\section{Maturana:}

O que vamos apresentar aqui é uma reflexão sistêmica.

\section{Ximena:}

Nós chamamos de sistêmica a reflexão que se dá no âmbito relacional no qual acontece o nosso viver.

\section{Maturana:}

O nosso viver está relacionado com os outros. O que vamos fazer são reflexões sobre as relações em nosso viver cotidiano, no âmbito profissional, no âmbito cognitivo, no âmbito familiar e que se relacionam com uma dinâmica que nos pertence.

\section{Ximena:}

A teoria sistêmica diz que o existir nos ocorre como um presente contínuo em contínua mudança. Passado e futuro não estão vencidos, são modos de viver o presente. $O$ passado nos diz do presente, ao olhar o futuro imaginamos um devir. Ou seja, o que nos ocorre é um presente em contínua mudança.

\section{Maturana:}

Se vocês pensam agora no que farão amanhã à esta hora, podemos dizer que agora estão inventando um devir. Podemos imaginar o amanhã a partir do presente vivido.

\section{Ximena:}

Ou seja, o futuro é uma maneira de viver o presente. Esta é uma das coisas que, em nossa cultura, não refletimos. Somos um presente em contínua transformação. Tudo o que somos nos acontece hoje em dia.

Além disso, um observador pode distinguir outra importante lei sistêmica: cada vez que um conjunto de elementos começa a conservar-se nestas relações, se abre um espaço para que tudo mude e todas as relações se conservem. 
Conferência. "Ética e desenvolvimento sustentável: caminhos para a construção de uma nova sociedade"

\section{Maturana:}

Que sucede? Se estudaram algo na universidade, em uma reflexão, podem recordar o momento em que começaram a estudar, começaram a conversar e a conservar um modo de viver esta relação com a universidade e todo o resto de suas vidas começa a mudar: o que comiam, o que conversavam, o que queriam, aonde viviam, a que horas se levantavam. Tudo começa a mudar e tudo começa a se conservar, neste caso, nesta experiência de viver.

\section{Ximena:}

O peculiar na teoria sistêmica é que cada vez que se distingue no espaço relacional o que se deseja conservar, produz mudanças. Não falamos de mudança por mudança, senão falamos de distinguir em nosso viver, em nossa dinâmica relacional, o que queremos conservar. Então, quando isso ocorre, um e outro mudam. Os processos humanos surgem, tanto definidos pelos desejos, como por preferências.

\section{Maturana:}

Nem sempre nos damos conta de nosso viver diante disso. Não nos damos conta de que o que fazemos, a cada momento, o fazemos por que queremos fazê-lo! Às vezes não queremos fazê-lo, porém o fazemos para conservar algo. A história evolutiva é uma história de transformações em torno da conservação do viver.

\section{Ximena:}

Os desejos se relacionam às entranhas. Se nós definimos o que queremos conservar, estamos de certa maneira fazendo evidentes, explícitos ou conscientes os desejos.

\section{Maturana:}

Nada é um percurso ou uma oportunidade em si mesmo. Algo é um percurso ou uma oportunidade só se o desejam. Às vezes, os percursos estão aí, por que não acontecem? Nada é um percurso em si, algo que se faz é um percurso, transforma-se em um percurso no momento em que exista o desejo.

\section{Ximena:}

Então, como produzir um viver congruente com a idéia de "Desenvolvimento sustentável e ética"? Para poder entrar nessa questão, necessitamos pensar quais são os fundamentos epistemológicos do nosso fazer? O que queremos dizer quando nos referimos ao âmbito do biológico e cultural do humano?

\section{Maturana:}

O que podemos dizer é que quando fazemos referência à história dos seres vivos, podemos compreender que esta é uma experiência e uma história de conservação do viver. E quando fazemos referência à conservação do viver, tudo tem mudado em torno da conservação do viver. Toda a diversidade do organismo, todas as distintas formas elementares e materiais de viver, tudo isto é resultado de mudanças em torno da conservação do viver.

Vou dizer outra coisa sobre o biológico. No âmbito do biológico, todas as formas de vida valem. Qualquer forma de viver vale enquanto se conserva. Qualquer forma de viver que se conserva até adiante, reproduzida de maneira suficiente, vale.

Qualquer forma de viver humana que se conserva na aprendizagem das crianças constitui o nosso saber emocional/cultural. Por vezes se diz à criança: - Não ponha a mão aqui! - Silêncio! Ocorre-nos dizer isto porque é necessário à conseqüência de seu viver. Existimos em um presente em contínua mudança.

Os seres vivos, em seu operar em sociedade, existem como uma rede fechada de condições moleculares que constituem unidades discretas que se produzem a si mesmas, continuamente. Sistemas moleculares se produzem continuamente a si mesmos.

\section{Ximena:}

Enquanto são seres vivos, em sua biologia vivem estes processos, mesmo sem se darem conta.

Tudo que fazemos em nosso viver está orientado a conservar este viver. E não fazemos nenhum esforço para o viver, o viver nos sucede, nos sucede de maneira espontânea. Nada disso se vive sendo dito, porém vivendo: fazendo o metabolismo, fazendo com que o coração bombeie sangue. Ou seja, o viver nos sucede e só tomamos consciência de nosso viver quando ficamos enfermos e queremos recuperar o que perdemos.

\section{Maturana:}

Nós nos organizamos na experiência do viver. Organizamos o social na experiência do viver. Os seres vivos, em seu existir como unidades discretas, operam como totalidades no espaço relacional, são organismos. Quando falamos em organismos, falamos de seres vivos em sociedade como unidades discretas em um espaço relacional.

\section{Ximena:}

E os humanos? Nós seres humanos somos organismos que existimos em um âmbito relacional que 
constitui um viver entrelaçado entre o emocionar e o linguajar, que é a dinâmica relacional que na vida cotidiana chamamos conversar. Ou seja, o ser humano surge no linguajar. O conversar é este entrelaçamento entre a linguagem e a emoção através do qual conseguimos mundos, geramos mundos em conversações. E podemos gerar um mundo ou outro de acordo com o fundamento emocional que estas conversações têm.

\section{Maturana:}

A linguagem se relaciona aos fazeres, não aos símbolos. O simbólico é um comentário sobre o que se vê na convivência em coordenação de coordenações de fazeres. A linguagem é este entrelaçamento de coordenação de coordenações de fazeres e as emoções em nosso viver cotidiano. Chamamos conversar (Com - junto - e Versar) o dar-se conta junto de um fazer e de um emocionar.

\section{Ximena:}

Uma fotografia pode congelar um instante do viver em uma rede de conversações. Ou seja, uma fotografia é um momento, porém pertence a um âmbito muito mais amplo, a um espaço emocional, a uma conversação: pertence a um momento da cultura.

$\mathrm{O}$ que distinguimos quando distinguimos cultura? Chamamos cultura uma rede fechada de conversações. Nós pertencemos a distintas redes de conversações em uma cultura, tal como a família.

\section{Maturana:}

Uma cultura existe na conservação da configuração do emocional que a distingue. O que estou dizendo é que toda cultura se relaciona a uma configuração do emocional. Por exemplo, as distintas famílias não podem reconhecer-se, uma vez que constituem espaços emocionais distintos. São modos de relacionar-se distintos nos fazeres da convivência. Uma cultura existe na conservação da configuração do emocional que a distingue e que se conserva em sua contínua transição no conviver das pessoas que a vivem.

\section{Ximena:}

É certo que nós mesmos, no viver que vivemos, geramos e realizamos a cultura que vivemos e a conservamos. Ou seja, não é uma cultura lá independente de mim. Então, a cultura que vivemos em família como rede de conversações gera e realiza, conserva um modo de viver e conversar que temos no interior desta família. Ou seja, cada um de nós é responsável pela cultura que realizamos no viver, seja em um âmbito local, que pode ser o de uma família, ou em um âmbito mais amplo de um devir como cidadãos.

\section{Maturana:}

Vocês podem pensar em um brasileiro ou em um chileno, nos diferenciamos em idioma, mas também em como nos movemos, em como reagimos. Não nos diferenciamos empiricamente, porém podemos dizer no agir em um espaço relacional que esta pessoa é chilena e esta pessoa é brasileira.

\section{Ximena:}

Uma cultura como rede fechada de conversações tem conseqüências no viver humano. Podemos gerar um mundo ou outro. Este mundo assim como é para nós, nós o geramos no viver que vivemos. Nós podemos gerar outro mundo. E também podemos ensinar nossas crianças a viver neste mundo como podemos ensiná-las a dar-se conta que geramos o mundo no qual vivemos. Isto pode produzir distintos modos de relacionar-se que têm conseqüências no viver humano. Uma outra cultura implica outro modo de conservar o viver, como relação. Nós temos um modelo de viver, um modo de refletir. A rede de conversações que nós realizamos em nosso viver local também tem conseqüências em nosso viver cidadão. Nós nos damos conta no curso de nossas reflexões que cada um de nós, na maneira que nos relacionamos em nossa família, está realizando uma cultura.

\section{Maturana:}

E nos damos conta de que este modo de relação, que está aí, é o resultado de uma rede de conversações! Quando alguém lê na Bíblia, por exemplo, a história da Torre de Babel. Podemos dizer que o que Deus faz supostamente neste caso, não é confundir os idiomas, é confundir as conversações. A rede de conversações que consistia nossas construções, o que podemos realizar.

Este seminário é resultado de redes de conversações sobre várias redes de conversações entrecruzadas no conviver de muitas pessoas. A noção de desenvolvimento implica o desejo de garantir uma idéia de completude. Desenvolvimento sustentável? Se nos referimos a um país supomos que deseje atingir em seus fazeres uma condição tal que seria denominada de desenvolvimento sustentável. Somente a palavra desenvolvimento traz consigo tudo isto na mão. Querem saber o que mais podemos fazer? Claro que espero que me escutem. A noção de crescimento se parece melhor, no sentido do aumento do tamanho de algo, quando este aumento do tamanho é visto como algo necessá- 
rio, natural. O que queremos? Crescer? Desenvolver-nos? Que estamos dizendo quando falamos isto?

\section{Ximena:}

Falar em crescimento nos remete a pensar que vivemos em um país que passa um período de transformações econômicas. Implica que algo está faltando, que não está suficientemente grande, suficientemente crescido, que não está suficientemente desenvolvido.

\section{Maturana:}

A palavra transformação é distinta. A palavra transformação faz referência ao que se conserva. São mudanças em torno da conservação de algo. Completamente distinto é dizer que estamos em um processo de transformação ou que estamos em um processo de desenvolvimento! Em um processo de transformação, nós estamos em um processo de crescimento. Quando uma pessoa encontra outra e lhe diz que está em crescimento, ela diz que está em transformação e faz uma referência ao âmbito do viver.

\section{Ximena:}

Desenvolvimento faz referência ao âmbito de uma vocação. Falamos em transformação na convivência. Falamos em desenvolvimento de uma criança e em crescimento. Falamos em transformação que se dá ao cabo de uma rede sistêmica em que tudo nos ocorre e nos conserva em contínua mudança. A definição de transformação faz referência a um olhar local/social. O que temos falado é em algo mais do que um olhar sistêmico, um olhar sistêmico recursivo, um olhar que aponta para os processos, para o que está ocorrendo e para o que não está ocorrendo. Sempre estamos nos transformando, sempre estamos vivendo.

\section{Maturana:}

Nós nos transformamos na conservação do que seja humano. As crianças se transformam, em processos de crescimento em torno da conservação de sua condição humana. Esta parte é central em nossa apresentação, o fato de dar-se conta sobre os aspectos desta dinâmica. De qualquer forma, estas noções são usadas em geral como se significassem pouca coisa, uma vez que cada pessoa ouve aquilo que quer ou deseja ouvir, ou aquilo que pode ouvir.

\section{Maturana:}

Se escrevermos: Vamos desenvolver o país! Cada um de vocês ouve algo diferente. Os diferentes modos de ouvir e de tomar decisões são valores igualmente válidos. O que nos espera não está determinado. Se nós buscamos uma definição, uma real definição, o que vivemos é um problema, é um conflito pelas diferenças de ouvir e agir.

\section{Ximena}

E temos o emocionar.

\section{Maturana:}

Teremos distintas orientações nos modos de agir no social. Os conflitos não pertencem ao âmbito da razão, pertencem ao âmbito emocional, ao âmbito do viver, do que nos ocorre enquanto se conserva.

\section{Ximena:}

$\mathrm{E}$ as emoções, que são as emoções? Entendemos que a nossa cultura nos leva a refletir sobre as emoções como sentimentos cíclicos, o que não é assim. Nos espaços de relações, as emoções são classes de condutas relacionais. Ou seja, em nosso viver, no espaço emocional, onde um e outro estão, na trama relacional desde onde surge um e outro. As emoções estão no curso dos modos de fazer.

\section{Maturana:}

Quando se escuta a mesma palavra com emoções diferentes, podem emergir distintas coisas. Cada um a sente de maneiras diferentes de acordo as suas coordenações de fazeres. O que conotamos ao falar de razão ou do racional são âmbitos dentro do social no qual se opera segundo lógicas definidas ou estabelecidas por princípios e condições relacionais aceitas a priori. Qualquer sistema racional se funda em premissas aceitas a priori. Qualquer argumento racional se funda em premissas aceitas a priori. As premissas aceitas a priori podem ser o ponto de partida, pois se não nos entendemos em torno de premissas fundamentais, não nos entendemos no viver.

Toda pergunta é um argumento racional em torno das premissas fundamentais aceitas a priori e envolve o emocional. Algo pode ser aceito como um princípio a priori quando não se aceita sem fundamentação racional, porque se alguém tem um argumento racional para aceitar algo como princípio, esta argumentação já tem um fundamento e um princípio que estão aceitos a priori. É interessante perguntar por que surgem os conflitos? Os conflitos que surgem de argumentações racionais contraditórias em relação a uma mesma situação não tem que ver com o racional, mas sim com os 
princípios que cada um usa para pertencer ao âmbito relacional.

É comum pensar que os conflitos estão ligados ao âmbito racional e convida-se a outra pessoa a revisar os princípios e os fundamentos em que ela surge, mas ao analisar os princípios descobre-se que se está fazendo uma coisa distinta do que desejava fazer.

\section{Ximena:}

Em muitas circunstâncias de nosso viver, a cada instante, o curso do que vivemos com os outros advém dos desejos, daquilo que se quer no viverconviver, não da razão. O que se deseja conservar socialmente? O que se deseja conservar como pessoa neste nosso viver-conviver? O que se faz em nosso viver relacional? Na teoria sistêmica temos conhecido o movimento dinâmico do desejo que, quando se distingue o que se quer conservar, tudo muda. O que cabe a cada um conservar na dinâmica do seu viver?

\section{Maturana:}

A coincidência do raciocinar implica na coincidência dos princípios, por isso grande parte da apresentação de um trabalho vai ser os princípios e fundamentos desde os quais está nosso fazer uma argumentação racional. Porém, há domínios em que isto aparece: nas políticas, nas doutrinas e nas ideologias que nunca se revisa de perto os fundamentos, a partir de que princípios fazemos as argumentações que consideramos racionais?

\section{Ximena:}

Como conversávamos, o central na vida humana é a conservação do viver, o que se quer fazer a estas pessoas. Não sei como será a tradução para o português, a relação entre os desejos explícitos e o sentir. Cada grande mudança em torno da conservação de algo em que uma quantidade muda o que temos é transformação. Estamos em contínua transformação. As crianças, quando os adultos lhes protegem, garantem esta contínua transformação. Nós, como adultos que estamos nesta dinâmica da conservação e, se vivemos, estamos nesta contínua transformação.

\section{Maturana:}

Aquilo que pode ocorrer com o ser vivo não está determinado, não está pré-escrito. A noção de sustentabilidade se refere à condição em um âmbito relacional.

\section{Ximena:}

A noção de sustentabilidade, na dinâmica da vida humana, só se atualiza na conservação das condições que fazem possível este habitar.

\section{Maturana:}

Então, se desejamos produzir isso - a sustentabilidade - o temos que fazer é habitar! Que habitar? O habitar é transformar! Na teoria sistêmica, cada vez que um conjunto de elementos começa a conservar-se em suas relações, abre-se espaço para que tudo mude e todas as relações se conservem. Condição central no sistema.

\section{Ximena:}

Como o que guia o viver humano são os desejos, eles surgem como os sustentáveis na realidade que se vive e que se deseja conservar neste habitar. Em uma cultura, nas redes fechadas de conversações, qual a centralidade nas orientações que se dão às crianças? A busca de êxito? A busca de competência? A busca da competitividade? Estamos cegos ao habitar humano, ao habitar em geral. O convite feito vai no sentido de abrir um espaço de reflexões sobre o que se quer conservar. $O$ que desejamos no viver e conviver? Qual é o habitar humano que desejamos com o conviver cotidiano? O futuro que deixamos para as crianças é fabricado na convivência. O que vamos deixar para os outros se dá na relação cotidiana.

\section{Maturana:}

No Chile, na dedada de 30 , quando minha mãe estudou serviço social, havia duas escolas, uma na universidade católica e outra na universidade laica. Diante de uma situação, por exemplo, de encontrar casais com filhos que haviam convivido muitos anos fora do matrimônio, as assistentes sociais da Universidade Católica queriam e se preocupavam de que esta família se legalizasse, que o homem e a mulher contraíssem matrimônio. Minha mãe observou que cada vez que isto se passava, estas famílias se acabavam. Minha mãe perguntava, por exemplo, aos homens: "Por que vocês não se casam"? "Porque se me caso, a senhora me põe chifres" - respondiam eles. E quando perguntavam às senhoras, respondiam: "Porque se me caso meu marido se torna bêbado" O que se passa com isto? O que se passava com o matrimônio? Mudava o que se conservava nas relações nestas famílias. Antes do matrimônio, tudo se conservava no encontro destas famílias. Cada um e os outros participavam deste mundo que haviam criado. Quando se casavam, começavam a querer conservar o que a lei do matrimônio dizia com respeito ao papel do homem e ao papel da mulher. 
Conferência. "Ética e desenvolvimento sustentável: caminhos para a construção de uma nova sociedade"

\section{Ximena:}

Então, retomando o tema da sustentabilidade pergunta-se: o que se deseja conservar para que tenhamos sustentabilidade? O que queremos fazer nesta dinâmica relacional-emocional.

\section{Maturana:}

A palavra sustentabilidade oculta muita coisa, certamente implica um dinamismo. Porém oculta um âmbito muito grande de emoções em relações, de desejos um tanto contraditórios. E cada um vai, em sua participação, com um firme propósito de fazer algo por uma convivência sustentável. O central é fazer explícito o que se quer conservar com a noção de sustentabilidade, porque há de se fazer explícito que estamos conservando aquilo que temos declarado que queremos conservar.

\section{Ximena:}

Ao fazermos explícito nosso desejo e o nosso fazer nos damos conta, enquanto assistimos os horrores, dos equívocos no caminho traçado em torno de nossos desejos fundamentais.

Se não nos damos conta disso, vão nos acusar de irracionais, de desonestos. O único que me ocorre é que temos sido mestres em conservar coisas distintas, onde o mesmo suposto está dado. Porém temos que ser sérios. Temos que fazer explícito, mas de que maneira? Cenas distintas em distintas circunstâncias, por suposto que outros podem nos dizer. Porém, se não fazemos explícito o que estamos dizendo com sustentabilidade, o que temos definido no âmbito do sustentável, não vamos alcançar nossos desejos.

Se queremos que isto se dê em uma situação pequena, seguramente é fácil, que nem sequer nos damos conta do que se quer conservar com esta noção em nosso país. O que está em jogo, a honestidade ou a ganância? A seriedade de fazer ou de resolver uma situação de urgência, por exemplo, a necessidade de habitação? No Chile, houve um período em que se foi olhar para o problema da moradia. Depois o que se estabeleceu foi que o central era resolver o problema da falta de habitação. Então se resolveu olhar a casa. O que mudou e o que se conservava era, por suposto, o mesmo tema.

\section{Ximena:}

Cada um pode fazer explícito o mundo que deseja em redes de conversações. Em que espaço emocional se dá as redes de conversações que desejamos? Em um espaço emocional em que seja possível a escuta do outro? Em um espaço emocional em que se exercite o respeito mútuo? O que nos ocorre e nos ocupa nesta reunião? Porque todos nós, no viver que vivemos, temos preocupações éticas? Porque nos importamos com o que se passa com os outros, buscamos tomar consciência das conseqüências de nossos atos. Sempre nos importa o que nos sucede.

Ao falar da vida nos referimos a uma preocupação que uma pessoa possa ter com as conseqüências do seu fazer sobre a outra pessoa, ou outro ser. Está relacionado com aquilo com o que o outro ou a outra faz em referência a mim. Não com a ideologia, não com a religião, mas com aquilo que se quer. Se um observador vê que uma pessoa se abstém de dizer aquilo que pudera resultar em dor a uma outra pessoa, ainda que ao fazê-lo resultasse em algo conveniente, se diz que esta pessoa se conduz de maneira ética, que tem uma conduta ética. Somos seres fundamentalmente amorosos. Porque o que queremos dizer é que esta é uma noção básica, o amor. Se cada um não desse importância para o outro não preocuparia para nada o que se passa.

\section{Ximena:}

Nossa ontologia constitutiva é de sermos seres amorosos. É preciso ver que realidade serve no âmbito da sensibilidade. Falamos em Biologia do Amor. Estamos acostumados a ver o amor com uma palavra relacionada ao ser romântico, aos afetos. Nós nos referimos ao âmbito da Biologia do Amar, o Amar-ação. Todos aqui, sem exceção, fomos acolhidos como bebês nesta confiança no mundo. Então, pensamos nas pessoas que têm sido terrivelmente autoritárias e perguntamos: Se vivemos o mesmo curso, o que se passou? É preciso ver as redes de conversações nas quais essas pessoas viveram e vivem no âmbito relacional.

\section{Maturana:}

Temos que ver as relações nas quais viveram estas crianças! Se vocês estudam a história da infância das crianças que se tornam delinqüentes, veremos que sempre elas vivem reiteradas situações de agressão e violência no espaço relacional.

\section{Ximena:}

Toda conduta ética está relacionada ao amar. Vamos fazer uma abstração do amar. Nós dizemos que uma abstração implica em um modo de viver. Cada um de nós surge no amar quando em uma conduta relacional eu mesmo e o outro e a outra surgimos como legítimos outros na convivência. $\mathrm{O}$ amar tem a ver com o ver, o amar tem que ver com o escutar. $O$ amar não se relaciona com as exigências em torno de uma expectativa. Ao falar dessa forma, quero dizer que retomo as questões: O que 
se deseja conservar? Se desejamos conservar uma determinada relação necessitamos recursivamente perguntar: essa relação que desejamos conservar faz sentido à rede social onde vivemos? Essa última questão é fundamental caso nosso projeto social não centre unicamente em cada indivíduo. Para isso, necessitamos nos escutar e o amar tem que ver com isso. Se avaliamos como não legítimo o que se disse, nós não escutamos. O escutar na biologia do amar implica que o que o outro disse é válido. Por que o outro sempre diz algo que tem vivido na convivência.

\section{Maturana:}

O escutar traz consigo a possibilidade do amor. Minha mãe morreu há um ano atrás com 101 anos e, antes disso, vinte anos antes, quando ela tinha 80 anos, eu lhe perguntei o que ela havia aprendido quando conviveu com uma criança índia boliviana. Ela me disse: Duas coisas: "colaborar e compartilhar". Porque colaborar e compartilhar implica em participar com os outros de um projeto comum, o que só é possível se, na convivência com o outro, possa ser visto e escutado, ser respeitado e respeitar.

\section{Ximena:}

Todos nós queremos conviver. Bom, queremos conviver neste mundo com respeito à participação nas relações com autonomia responsável em nosso fazer? Ou queremos conviver na obediência, na falta de reflexão sobre si mesmo, na dependência irresponsável?

O que fazemos com a questão social? A história do século passado está impregnada com a intenção de gerar uma ordem social e isto produziu alguma ideologia e alguma teoria que, se geraram estes intentos, também geraram sofrimentos.

Pensando sobre essa apresentação, fizemos aprofundamentos amplos e dissemos que a questão social está vinculada com um olhar amplo, sobre a trama relacional e a trama emocional, o que se faz, o que se quer fazer. Nada se vai lograr se não se faz um olhar sistêmico.

\section{Maturana:}

Não estamos fazendo uma recomendação! Estamos dizendo que se isto não acontece, o outro não passa, porque onde não se escuta, não há espaço para a participação.

\section{(Aplausos)}

Gracias.
Pergunta: É possível utilizar a noção de autopoiése relacionada a outros sistemas, por exemplo, aos sistemas sociais?

\section{Maturana:}

Somos um presente em contínua transformação em torno da conservação do viver. Todos os processos do mundo natural são espontâneos. Nós os seres humanos constituímos uma anomalia. Nossa conduta é anômala e tem gerado anomalia. Sobre isto, podemos refletir perguntando o que fazemos e por que, segundo nossos desejos por um caminho ou outro. A dinâmica social surge espontaneamente. Aparece no sistema quando o que surge não dá conta e queremos mudá-lo. O que nos surge se vai dando espontaneamente, surgem os fatores, nós desencadeamos em nós o desejo de fazer algo distinto o que implica em mudar a convivência com o outro. O tema vai aparecer quando um e o outro dizem que o que estamos a viver não gostamos. É claro que este algo se decide somente quando se vê claro. O momento em que se vê isto claro, isto se revela. Ou seja, o que passa com os seres humanos e que é peculiar é a ação que surge consciente, o que cada um quer ou não quer viver o que está vivendo. Esta ação consciente de mudar o que estamos vivendo surge de uma maneira ou outra.

\section{Ximena:}

A pergunta, assim eu a escutei:_Se é possível utilizar no âmbito do social a noção de autopoiése? Nós dizemos que não. A autopoiése dá conta do fenômeno do vivo. E o espaço do social é um outro domínio.

\section{Maturana:}

Agora entendi um pouco mais a pergunta. Uma família é constituída por seres vivos. Se eu a vejo com as pessoas que constituem uma unidade, podemos dizer que temos um sistema autopoiético de $3^{\mathrm{a}}$ ordem constituído de seres vivos. Se eu digo a uma pessoa que sim, que um sistema social é um sistema autopoiético, estou usando a noção de autopoiése que no fundo não se aplica. Uma família é um sistema autopoiético de $3^{\mathrm{a}}$ ordem. Isto não é central na família. O central em uma família é uma relação interpessoal. Então, posso aplicar a noção de autopoiése mais lá onde estão constituídos como unidades discretas os seres vivos. O central nos grupos humanos surge na convivência. Porque os seres humanos são conscientes. Nos perguntamos se queremos o que estamos vivendo, ou não. 
Conferência. "Ética e desenvolvimento sustentável: caminhos para a construção de uma nova sociedade"

Humberto Maturana Rosesín é Ph.D. en Biología, Universidad de Harvard. Co-fundador Instituto de Formación Matríztica. O endereço eletrônico do autor é: maturana@matriztica.org

Ximena Paz Dávila Yáñez é Orientadora Matríztica, Co-fundadora Instituto de Formación Matríztica. O endereço eletrônico da autora é: ximena@matriztica.org

Recebido: 08/12/2004

1a-Revisão: 20/12/2004

Aceite Final: 15/01/2005 